\title{
On the integration of physical education and sports resources in Colleges and Universities
}

\author{
Wei Wen, Peng Zeng \\ Nanchang institute of technology,Jiangxi,Nanchang,330044
}

Key words: competitive sports; resource integration and optimization

\begin{abstract}
: using the questionnaire and literature method, the study on how to realize the interactive development of the school sports and the regional sports in Beijing city is carried out in order to realize the interactive development of the school physical education and sports in Beijing city. Research put forward, make full use of competitive sports resources in Beijing City, improve the quality of students, increase the training funds, improve the training conditions; to play the advantages of colleges and universities, transfer training environment, take the road of training, research and education integration.
\end{abstract}

\section{Question put forward}

After the success of the Beijing Olympic Games, Beijing sports entered a new stage of sustainable development as the main content and characteristics. In the new period, college sports how should after the Olympic Games, the athletics of school sustainable development requirements, proposed the new challenge to the school sports, how to hold the Olympic Games held in the favorable opportunity, how to further use of the Olympic Games on Beijing sports, Beijing University of sports toward the healthy and sustainable development, Beijing City College Physical Education Development in urgent to solve the problem. For this purpose, this research mainly discusses how to serve the competitive sports of Beijing city in Beijing, in order to realize the interactive development of school physical education and regional sports.

\section{2 research method}

\subsection{Literature data method}

Through China National Knowledge Infrastructure and network resources collection, identification and finishing college PE resource integration and optimization of literature, lay the foundation for the analysis and discussion.

\subsection{Investigation and research method}

The main use of visits and questionnaire survey method to carry out the actual investigation. According to the need and the main content of research design "Beijing University high level sports team building" the investigation of Beijing University high level sports team were investigated, in order to understand the current situation of Beijing University high level sports team.

\subsection{Mathematical statistics method}

Using statistical processing software for statistical processing of the relevant data. 


\section{Results and analysis}

3.1 Connotation of integration and optimization of physical education resources in Colleges and Universities

"Integration" is mainly defined by the system of overall and core system unifying, condensation and lead to make some related departments or factors in the synthesis for a new unified the whole building, the ordering process. From the point of view of regional development, the characteristics of sports colleges and universities in Beijing area performance internal relative homogeneity, the social and economic background of the development of university sports is close to, educational activities in the same location, similar educational resources, educational development level are very similar. At the same time, the University Sports in the region has a relatively independent management and coordination mechanism, the policy has consistency and continuity, and the coordination of school sports and economic and social development of the relationship is relatively easy. From this level of speaking, interactive development of school physical education area, mainly refers to the in the social, economic and educational factors such as relative homogeneity conditions, within the areas of Beijing City College Sports and athletics sports and the social sports overall interactive development. From the perspective of the development trend of modern education, school physical education should provide services for the development of regional sports, school sports and Regional Sports Interactive development. In certain areas, college sports resources collection, synthesis, integration, integration into a harmonious whole, that "the whole is greater than the sum of its parts", and give full play to the overall effect, reach the best benefit of education, this is college sports resources intergration and optimization. Process integration need to follow the principle of optimization, pursue optimization benefits, will take to optimize the benefits, and integration and optimization is the cause and effect relationship, mutual joint together. From the point of view of ecology, regional college sports resources integration and optimization is sports resources and the optimized combination, to establish the alternate, complementary, and fusion, the sustainable development of the ecological relationship between the sports resources in Colleges and universities, so as to promote the regional sports benefit.

\subsection{University of Beijing city service exists in Beijing City Sports problems}

\subsection{1 internal and external mechanism of the problem}

External mechanism is refers to the administrative department for physical culture and sports emphasis on Physical Education in Colleges and universities, physical education in Colleges and universities as Beijing sports personnel training, participation in scientific research and service ability of recognition, which is college sports can Beijing Sports contribute an important prerequisite for. Internal mechanism refers to the institutions of higher learning for its own advantage propaganda and self perfection, colleges and universities should seize the opportunity to increase their propaganda, the advantage of external understanding of physical education in Colleges and universities. The coordination of internal mechanism and external mechanism should be played to promote the sports in Colleges and universities to serve the competitive sports in Beijing city.

\subsubsection{Sports training system reform problem}

Competitive sports colleges and universities is a new exploration of the construction of competitive sports management system with Chinese characteristics, is a pioneering undertaking, but also a complex system engineering. Colleges and universities should fully understand the current situation and tasks of the development of competitive sports in China, so that the management mechanism of competitive sports and general education management mechanism. At the same time, by the success 
of held Olympic Games it, learning and foreign colleges and universities sports training, successful experience of talents of high quality and high level of athletic talents cultivation, to establish our country athletics sports development of network training.

\subsubsection{The allocation of resources to further optimize the problem of}

The universities and colleges in Beijing must break the boundaries between the current fragmentation pattern of universities and colleges, and in the management and use of resources to implement the integration and sharing of resources, achieve the complementary advantages of resources, give full play to the greatest efficiency of limited resources. In the layout of the project to comply with the planning of the development of competitive sports in Beijing, fully on the basis of the training advantages and scientific expertise and biogenic conditions factors, as far as possible to avoid the overlapping set of, in the human resources training, colleges and universities to do a primary and a light weight, to the advantage of project based, supplemented by other projects. At the same time, universities should strengthen the communication and cooperation between each other, so as to achieve the complementary advantages of resources, but also to achieve the sharing of resources.

\subsection{Measures for the development of competitive sports in Colleges and universities in} Beijing

3.3.1 Reached an agreement with the Beijing Municipal Sports Bureau, attaches great importance to the Sports College of

According to the movement characteristic of the Beijing City, the existing high level athletes, the dissolved has the characteristics of the project of colleges and universities, draw lessons from the foreign high level athlete's growth and success, combined with Beijing existing economic conditions, the level of sports, and the favorable environment, the Beijing Municipal Education Commission and the Beijing Municipal Sports Bureau leadership should be far sighted, idea innovation, forge ahead, to accelerate the pace of reform, increase the investment, pay more attention to sports to the development of colleges and universities, and gradually increase in Institutions of higher learning oriented society competition ability, highlight the school characteristics.

\subsubsection{The innovation of the competition system}

Sports competition is a lever to test the effect of the training of college sports teams. Sports competition is the engine to promote the level of competitive sports in Colleges and universities. Our country at present stage university high level sports team, one year can only participate in the two competition, namely provincial city level university student (or single) sports meeting and national university student (or individual) sports meeting. In developed countries, the annual college frequent matches between universities and universities competition exchange continuously. Take the American college basketball game as an example, according to the information shows: they are in a different level of competition in the year, the number of appearances of 52 games. Obviously, our existing system of college students has been limiting the development of high level sports teams in Colleges and universities. We urgently need to strengthen the construction of the sports associations of college students, play the role of the sports associations of college students, improvement and implementation of "Olympic strategy" harmonization of college competition system.

\subsubsection{Perfect competition system}

The development of competitive sports has a close relationship with the perfection and development of the competition system in a large degree. Generally speaking, high quality, reasonable, perfect sports competition can promote the improvement of sports training, and no systematic, high level of sports training, it is impossible to have a high quality of the competition. It 
can be said that the perfection and development of the competition system and the improvement of the practice level of the sports training are mutual and complementary. College students sports competition system is the driving force for the development of competitive sports in Colleges and universities, and is the key link of the coordinated development of high level sports teams and China's competitive sports. To learn from foreign advanced competition management experience, combined with the State Sports General Administration of competition system, take full advantage of sports socialization, market opportunities, and constantly improve the system of College students. We renew ideas, deepen reform, set up a set of scientific and rational management system of high level sports teams in Colleges and universities, in order to realize the goal of Beijing City College Physical Education in Beijing city. (1) the use of the market, relying on the community, to promote the university students' League system. On the basis of summing up the successful experience of domestic and foreign sports competitions, the competition system is divided into several levels. According to the sports level and scale of the colleges and universities in Beijing, it is divided into a group of a, B and C to carry out the competition, and the competition period of College Students' sports meeting is shortened (2). The World University Games competition is held once every two years, the National University Games game settings should be held two years session and in the same year, the World University Games will pre race held is more reasonable, not only can the increase in the number of high standard games, testing the effectiveness of training and to participate in the World University Games team prepare pre selection of work; (3) establish a set by Beijing, and other provinces and cities, the national and international four levels of university athletics sports competition system. (4) the university sports competition should enter the main channel of Beijing city and national sports competitions, and encourage all colleges and universities to participate in various competitions held by the sports bureau system. For holds a session of the national sports meeting every four years, all colleges and universities should be in Beijing as a unit alone team participate in the competition. For each sport in Colleges and universities should alone team to participate in the competition. $\quad 3.3 .4$ Make full use of sports resources in Beijing City, to improve the quality of students

At present, the high level sports teams in Colleges and universities of our country students mainly from the provinces of high level sports teams and sports schools and some advantages of traditional sports of middle school. In the reform of competitive sports in transition period, in order to avoid the loss of excellent athletic sports talents, colleges and universities in Beijing should be according to the characteristics of the competitive sports development, and body work team, on sports school, the traditional advantages of sports school reached enrollment agreement, guarantee the quantity and quality of the students, so as to avoid the outflow of Beijing high level athletes, and high level sports teams in Colleges and universities talent fault phenomenon.

\subsubsection{External full-time coaches, ensure the training effect}

Physical education in Colleges and universities from the nature and the training of college sports teams have obvious differences. At present most of the Beijing University high level sports team coaches for the school physical education teachers, the majority of PE teachers lack training team big game experience guidance, to avoid detours, early yield, institutions of higher learning in the competition and training institutions should be according to the actual, formulate preferential policies to foreign hire full-time coaches, and strengthen the headed to the University of the theory and practice of coaches post training, optimize the structure of coaches, to ensure the training effect, so as to improve the athletics movement level " 


\subsubsection{Increase training funds, improve the training conditions}

Ordinary university sports team funds are mainly higher funding, school sports funding, corporate sponsorship and sports department self several sources; expenditure including costs of coaches, equipment, athletes equipment fees, meals and other expenses. At present, the vast majority of colleges and universities in Beijing, there is a shortage of funds. In addition to higher authorities and school funding, colleges and universities should and Beijing some sports enterprises, sports clubs and even other industries reached a mutual agreement, with corporate sponsorship to increase training funds, expanding the sources of funds, improve the coaches of welfare, the subsidy for athletes and training practice necessary hardware facilities and other training conditions.

\section{Conclusion}

In order to improve the scientific level of Beijing high level sports teams in Colleges and universities high level sports team sports training, sports scientific research resources in the integration and utilization of capital, fully mobilize and play levels, the capital of the scientific research departments and all levels of colleges and universities scientific research strength, including personnel and equipment and related technical services and scientific research team, joint research. Sports scientific research not simply for the published papers and research, but to meet the movement first team athletes need to conduct scientific research and technical service, give full play to the role of modern science and technology in competitive sports, improve the level of competitive sports. In scientific research and scientific and technological service of process, the professional quality of the large number of scientists will improve, especially the improvement of colleges and universities sports scientific research personnel quality, the construction and development of the subject plays an important role in promoting.

\section{Reference:}

[1] Zhang Yuguo, Li Jia Jiang. Journal of China University Sports Events resource allocation imbalance and countermeasures [J]. Shenyang Sports Institute. The 2014 (02).

[2] Zhang Yuguo, Li Jia Jiang. China University Sports Events resources optimization allocation of -- to College Basketball League for example [J]. Journal of Beijing University of physical education. 2013 (11)

[3] Zhao Shushan. Allocation of higher education resources ecological imbalance analysis [J]. Heilongjiang higher education research 2012 (09).

[4] Zhang Shouwei, Li Jia Jiang. Heilongjiang our school athletics sports development research logic basis and value orientation [J]. High teaching research. 2012 (2009)

[5] Tian, Mingxuan, Zhang Shouwei. Of Journal of Harbin Institute of physical education in China school sports development characteristics analysis [J].. 2011 (03) 